\title{
Rereading to Rewrite: Documentation and Requalification of Mediterranean Historical Centers, Jerusalem and Taranto Case
}

\author{
By Stefano Bertocci* \\ Monica Bercigli ${ }^{\dagger}$ \\ Matteo Bigongiari ${ }^{*}$ \\ Vincenzo Moschetti ${ }^{+}$
}

\begin{abstract}
The contribution concerns the possibilities of utilization of the digital technologies focused on the documentation of the historical centers. The aim of the project is to evaluate the conservation status of the Heritage and the possibilities and opportunities of valorization and requalification of the historical urban core through projects that show a high level of compatibility with the environment. In relation to these methodologies grows the need to take the inhabitants back to live again the historical center creating spots of complete requalification through the instruments of the architecture. The reading of the places in complete or partial decay and abandon status wants, hence, to get the basis for the preservation of them through precise interventions so that they can create significant synergies in which the inhabitants - through the architecture and their life - come back to inhabit that is to live again those places that, otherwise, time would take away letting forget and lose to the world extraordinary parties of landscape.
\end{abstract}

\section{Introduction $^{1}$}

This paper reports two experiences of documentation through integrated digital survey methodologies and the planning experience of little areas of historical city in the Mediterranean Area.

In the last decades, the need to rehabilitate the historical center of the old city of Taranto has grown, creating spots of complete requalification through the instruments of the architecture. The "reading" of the places in complete or partial decay and abandon status wants to get the basis for the preservation of the Heritage. This is the premise for the development through precise interventions so that they can create significant synergies in which the inhabitants - through the architecture and their life - come back to inhabit that is to live again those places that, otherwise, time would take away letting forget and lose to the world extraordinary parties of landscape.

There is also a case study of the district of East Jerusalem, which develops

\footnotetext{
*Professor, University of Florence, Italy.

${ }^{\dagger} \mathrm{PhD}$ Student, University of Florence, Italy.

${ }^{\star} \mathrm{PhD}$ Student, University of Florence, Italy.

${ }^{+} \mathrm{PhD}$ Student, University of Florence, Italy.

1. The author of this paragraph is Stefano Bertocci.
} 
from the stretch of the ancient city walls between Damascus and Herod Gates. The urban system, built in the first half of the twentieth century, is constantly changing and has as its main roads Sultan Suleiman Street, which runs in front of the perimeter of the ancient walls, and Salah Eddin Street, which penetrates perpendicularly in the urban fabric. This district originally developed in the building space between the walls and the cemetery of Bab Azhar, beginning to build from the gate of Herod to that of Damascus, and then the expansion continued to the East. For the purpose of the construction and urban renewal project, morphological documentation and diagnostic and structural analyzes have been concentrated in this area of the city of Jerusalem, to arrive at the drafting of a design proposal that preserves local history and culture.

\section{Background: The Contribution of the Digital Survey for Redevelopment Studies of Historic Centers ${ }^{2}$}

This research is based on experiences gained over several years in various Italian study cases concerning the planning and conservation problems of historical centers, with particular reference to the issue of the development of a scientific knowledge framework that starts from the tools of digital survey. Our research team has experimented methods and working protocols that, starting from reliable digital surveys (primarily through 3D laser scanning methodologies) allows the documentation and the analysis of the constitutive and characterizing aspects of the urban construction fabric, as well as the documentation of the state of conservation and the main criticisms of the buildings that constitute them. Just to mention some examples: the Plan of Functions of the historical center of Montepulciano, in the province of Siena, realized in 2012; the cognitive framework of the Reconstruction Plan of the historical center of Terranuova Bracciolini in Valdarno area; the considerations of seismic vulnerability for the historical center of Poppi (Arezzo), a municipality of the Apennine area (Casentino) with seismic risk; the Reconstruction Plan of the village of Acciano (L'Aquila), a city in the Abruzzo region, hit by the earthquake of 2009. The redevelopment of an urban fabric, also of historical value, provides three prior analysis phases: the digital survey on the urban scale of the historical center, the mapping of the buildings, realized through a historical-documentary research on the urban fabric with adequate analysis of construction techniques, and the realization of a "masterplan" which considers the relative assessments of the stability and vulnerability of the structures to meet the safety conditions. The integrated survey project is planned and organized in different stages and levels of knowledge, based on the urgency of the first intervention actions. For historical center surveys, the need to use the most advanced techniques such as the use of terrestrial laser scanners and low-altitude photogrammetric system (like drone) is increasingly evident; these methods can produce highly reliable cartography, supplemented by digital drawings, virtual reality and GIS applications. In the acquisition of digital documentation it is important to certify the data obtained with these technologies and to observe a

2. The author of this paragraph is Stefano Bertocci. 
methodological protocol that ensures a minimum error in the final database. The in-depth functionality of building an integrated system of knowledge of urban structures and aggregates, both in terms of architectural and environmental value assessment, as well as knowledge of the actual conditions of the structures, is essential for the planning of interventions. The use of the technologies described above will also provide an effective database for the future monitoring of historical centers. It is necessary to build a database of census data for individual building units where architectural, cadastral, structural data, stability considerations, drawing pictures etc. are inserted. The database will then relate to the cartography and the 3D model for the creation of thematic maps. In addition, the geological and seismic analyzes are crucial to acquire the knowledge of the territory and its criticality. The case studies selected in the Mediterranean area show what happens on the opposite shores between Taranto (Italy) and Jerusalem (Israel). These are current themes, especially in relation to the possibility of recovering ancient human settlements intended to abandon and decay but nowadays still full of important aspects concerning the local economy, structural stability and the inhabitant's safety.

\section{The Case Study of the Old City of Taranto: From the Survey to the Project ${ }^{3}$}

The study area, a portion of the old city of Taranto overlooking the Small Sea, the waterfront overlooking the Small Sea and the urban fronts of Via Di Mezzo between Discesa Vasto and Vicolo Via Nuova, appears visibly degraded and reveals, the architectural and social fragility of a whole city. The close relationship that the city has with the sea and with the activity related to it, makes it necessary to protect these spaces and therefore the planning of interventions, through structured documentation, for the preservation and valorization of all those which are the peculiarities and the features of the place.

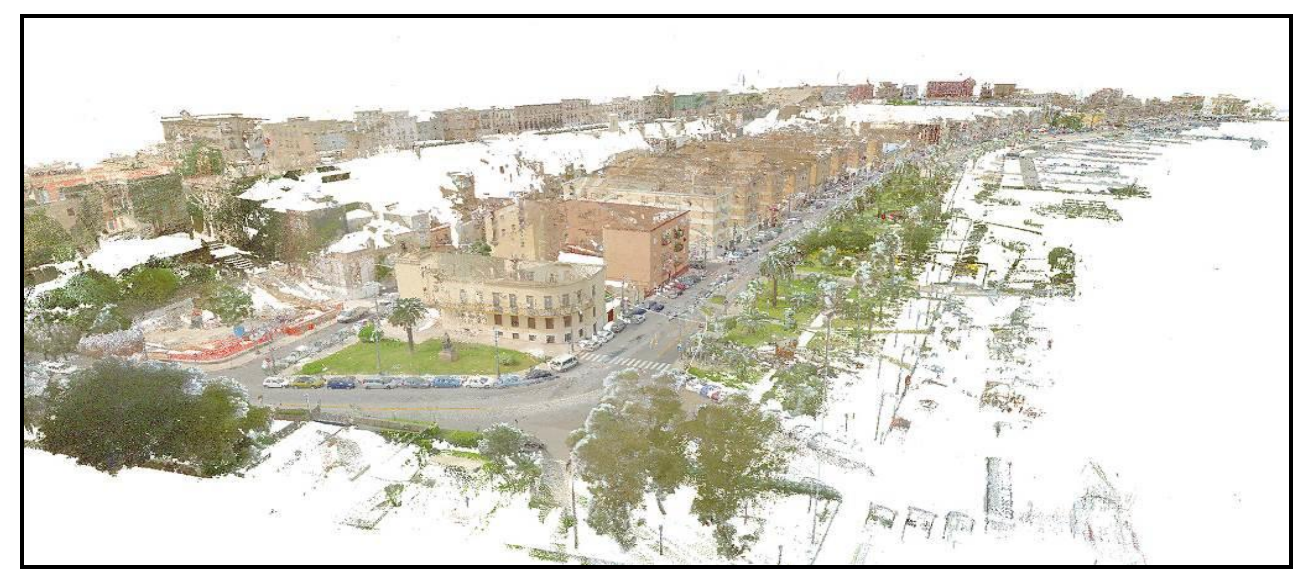

Figure 1. Point Cloud of the Entire Island of the Old City of Taranto made by Laser Mobile Mapping

3. The author of this paragraph is Monica Bercigli. 
The survey, carried out through integrated methodologies with the experimentation of laser "mapping mobile technology" (Figure 1) in relation to Structure From Motion survey techniques (SFM), has allowed to realize for the first time a unique survey of the external profiles of the entire island.

The comparison with the static laser scanner, the verification of the reliability of those procedures and the integration of acquired data through photogrammetric techniques, have allowed us to make a series of reflections on the drawings of the urban survey and on their translation into useful representations to the redevelopment and redesign of a portion of the city (Figure 2).

We proceeded starting with the static laser scanner survey by performing 67 scans, with the Leica Z + F 5006h tool, for the section of Via di Mezzo and the St. Joseph Church. Through the mobile laser was acquired, as well as Via di Mezzo, also the road that runs along the perimeter of the island. One of the biggest mobile laser survey advantages is to be able to acquire a large number of points in a quick time, shortening in a significant way also the timing of post-production of the point cloud, because all the scans have already the same reference system, and are already 'aligned'. The large portion of the city acquired by mobile also facilitates the realization of drawings for a general overview, useful for the study of the urban settlement and for the relationship between the project spaces. The main aim of the experience was to conduct some tests on photogrammetric applications through the use of "mobile camera" and so some spherical photographs were acquired throughout Via Di Mezzo thanks to a camera provided with mobile laser tool.

Then we proceeded with traditional photo sessions, made with digital camera Nikon D3000, in order to compare the products. The following table shows the obtained results on a portion of buildings, and reports some considerations on the reliability and accuracy of the different methodologies. In Figure 2, image A, we can observe the evolution of acquired data through traditional SFM survey through 52 photographs. The point cloud consists of 4.942 .093 points and the mesh of 144.430 polygons. In the image B we can see the same sequence related to the acquisition via mobile that has generated, through 68 photographs, a cloud of 8.905.486 points and 92.756 polygons.

The reported experience in the following paper highlights how the 'Mobile laser' technology can be a valuable tool for the urban survey, both in the point cloud that results, and for the application of photogrammetric techniques. All the drawings in fact, when used on an urban scale, provide all the metric and material information that we need.

4. Engineering commonly used technology, for the detection and monitoring of infrastructure. The used system, laser Riegl VMX 450 for the earth's dynamic survey allows moving detecting at speeds up to $100 \mathrm{~km} / \mathrm{h}$ the territory at $360^{\circ}$, rebuilding it on real-time and returning a 3D survey with $8 \mathrm{~mm}$ accuracy and $5 \mathrm{~mm}$ precision. The equipment used was granted by Sineco S.p.A company. 


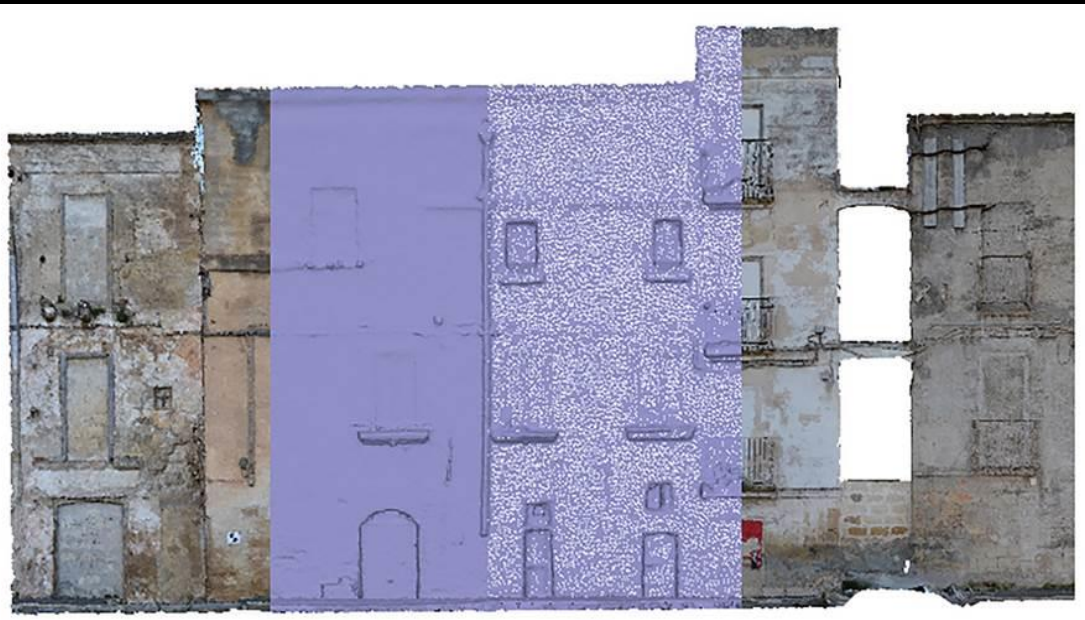

A

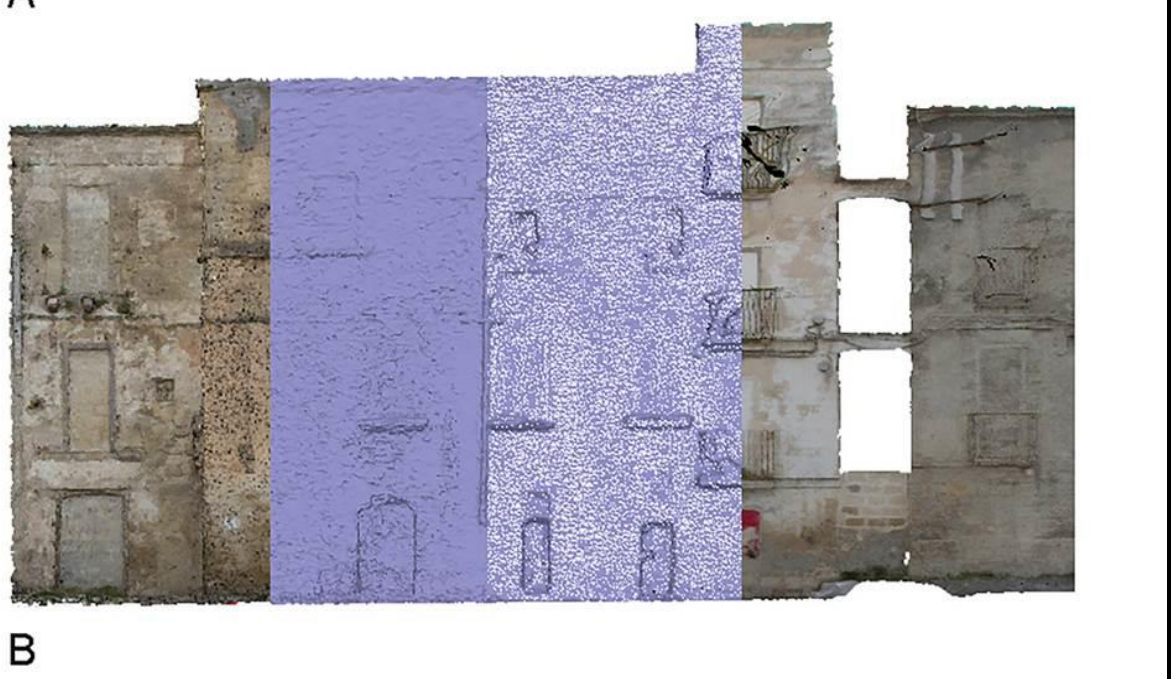

Figure 2. In the Image A, the 3D Reconstruction Process through the Software Agisoft Photoscan of the Survey Carried out by the Nikon D3000. In the Image B that Performed through the Camera Included with the "Mobile Laser". In Both Cases, on the Left the Dense Cloud, then Two Kind of Visualization of the Mesh and Finally the Application of the Texture

The documentation (Figure 3) that comes out is made up of traditional 2D drawings and 3D models, everyone are a detailed representation of the buildings claiming spaces, modes and functions of the urban fabric of the Old City and decisively clarifying the useful elements for the development of future projects. The interoperability testing between traditional tools and mobile laser technology has opened new avenues for the development of what we might call 'expeditious survey' in the field of Cultural Heritage, thus speeding up the processes of acquisition and documentation of the urban centers according to a redesign of the same.

"The drawing function is [...] to assign to the buildings and to the parts which compose them, an appropriate location, an exact proportion, a convenient arrangement and a harmonious order, so that the whole shape of the construction 
entirely rests in the drawing itself."

The way to observe at the buildings of an experienced architect is not too different from the one who lives the city every day. Today, communication and enhancement of Cultural Heritage are supported by an integrated methodological approach that uses digital technologies. These instruments used to represent the colorful Via di Mezzo have allowed to capture in detail the geometry of the houses, or what remains of them.

One of the challenges of the scientific community in last decades is to find an effective method for the material and immaterial preservation of historic centers and urban monumental systems, thanks to the use of digital technologies. The integration and the dialogue between information systems is contributing to the development of more and more articulated databases that find in connection mode the possibility of defining management and planning systems of urban centers.

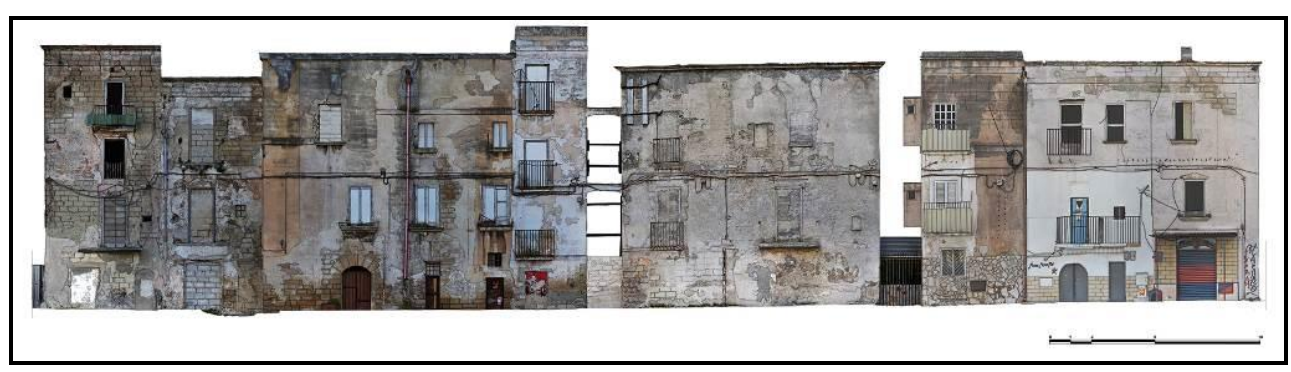

Figure 3. Materical Drawing Realized through Traditional SFM Method. The Present Study was carried out by G. Giannetti, C. Livi, V. Mugnai within the Course of Surveying Architecture A.A. 2016/17 by Prof. Stefano Bertocci

The database produced by metric and photographic surveys is a data archive on a part of the old city that allows endless readings, but they need to be sorted and subjected to interpretative processes in order to extract themed information. The schematization of the themes has addressed the synthesis and analysis process, facilitating both the collection of data and their interpretative reading through censorship and cataloging. Census sheets for the cataloging of urban fronts were made based on a careful study of the previous drawings and on the information collected in loco. The census sheets contain information describing the buildings, both their state of conservation and their relationship with the road. Following the compilation of the census sheets, they were inserted into a questionable digital database to create thematic maps that serve not only to catalog the buildings in an orderly way, but also to understand how the single artifact interacts with what surrounds it.

The census sheets used during this work were divided into seven sections, the first of which related to general information about the building. First, the building code is given together with the storage code, related to census sheet. The sheets contain information regarding the location of the building, its architectural typology, the use of the ground floor and the number of floors. The second section refers to the external physical analysis, which concerns technological and

5. L. B. Alberti, "De Re Aedificatoria," in Trattati di Architettura (ed.) R. Bonelli and P. Portoghesi (a cura di) (Milano: il Polifilo, 1966), 7. 
typological aspects. In this part the constructive and material features are given, together with some information about the coverage. The third section concerns the analysis of the urban front, it provides useful markers in order to describe the presence of sheds, loggia, overhangs and more. The third section concerns the analysis of the urban front, it provides useful markers in order to describe the presence of sheds, loggia, overhangs and more, highlighting moreover the presence of architectural precious elements. The next section, the fourth, deals with the analysis of degradation, starting from the coverage and the masonry, to the degradation of the window frames. In the fifth section there are information concerning the façade installations, such as chimneys and pipes, but also the presence of lighting system and storefronts. In the following sections, in addition to colorimetric information and photographic references of the building or significant elements, there are markers related to the socio-cultural and environmental analysis of the building. It means the classification of the building according to public or private use, the accessibility of the main entrance as well as the presence of "incivility" signs, such as graffiti, murals and accumulation of dirt. The result of all these important operations is a documentary corpus of fundamental importance, in order to better know and understand the site, and its following and eventual redevelopment. The products of this work are a point cloud (a three-dimensional representation of reality), and two-dimensional drawings, which describe the degradation and reveal the fragility of the city, both architecturally and socially. Time seems stopped in the old city and the use of digital technologies triggers a process of strengthening the knowledge of the identity heritage to promote socio-economic development, conscious tourism flows and collective consciousness over cultural goods. Every inhabitant, every child, imagine every day the place where he would like to live. The virtual "is one of the oldest and most fervent dimensions of architecture and the main cultural goods of contemporary creativity." ${ }^{6}$ Everything that can be imagined can be also drawn and represented. The research experience held in Taranto has allowed students to develop project proposals based on precise and accurate surveys, giving them the chance to relate with a place they have experienced and deepen day by day. As Pierre Lévy suggests, "the virtual tends to get actualized, without however being passed on to actual or formal concretization. The tree is virtually present in the seed." ${ }^{7}$ The renewal that the old town needs is already visible in the city itself, in its cracked buildings, in its disjointed asphalt and in the enthusiasm of the children who live there. The Survey and Representation disciplines cannot ignore the relationship and the bond created by their final use. Furthermore, the propaedeutic drawings for the 'develop' of a new project need not only to collect all useful metric and material information, but must be made bearers of the suggestions of the place.

\footnotetext{
6. M. Unali, Atlante dell'abitare virtuale (Roma: Gangemi, 2014), 18.

7. P. Lévy, Il virtuale (Milano: Raffaello Cortina, 1966), 5.
} 


\title{
Inhabiting Amnesia. \\ Reconstructing a Place through the Architecture of the Real ${ }^{8}$
}

\begin{abstract}
"Furthermore, - it says in 'Del sito della Giapigia' - the city located in that recess of the Gulf of Taranto is enclosed by land; on one side the promontory of Iapigium and on the other the promontory of Lacinium, where the Gulf of Taranto ends. It lies seventy miles from Iapigium and one hundred and thirtysix from Lacinium; since it is surrounded everywhere by the sea it can be called Mediterranean ",9
\end{abstract}

To forget. What happened to those words from the Galateo? The most acute form of forgetfulness originates at this point, the most vital amnesia, the most moving of lost memories in which the urban fabric and the city as a whole, beyond the navigable canal, ${ }^{10}$ no longer recognise themselves in this sea.

It was decided to look in another direction, to welcome heavy industry which since the Sixties began to erase the traces of centuries old olive groves, tangible memory of travelers who arrived in Taranto, which once was the capital of Magna Grecia and had lived moments of indescribable ${ }^{11}$ splendor. The long rows of trees drew a landscape that remained engraved in the maps of aristocrats from all over Europe, in unforgettable images capable of transmitting a timeless truth. Thus when the new erases the ancient the dance of time becomes invisible, is interrupted. It was decided to erase the sea and its infinite blue horizons which connected parts of the paese to parts of the landscape: the Mediterranean. It would have been nice to begin this narrative with Carlo Belli's words, listening to them and making sure that they silenced any other superfluous thought. It would have been truly wonderful after all - as he wrote more than a few decades back "narrowing the eyes, to be able to imagine the true Tarentum".

8. The author of this paragraph is Vincenzo Moschetti.

9. A. Galateo, Del sito della Iapigia: Epistola (Napoli: stamp. di Gaetano Rusconi, 1853).

10. The Navigable Canal has divided since the Aragonese period the "new" city, known as Borgo Umbertino, and the island of the Old City of Taranto. The Navigable Canal connects the Mar Grande with the first cove of the Mar Piccolo. Ferdinand I of Aragon made it deeper and enlarged it when the Turks, having laid siege to Otranto in 1480, threatened to attack Taranto. Philip II made it navigable; Ferdinand I of Bourbon bettered it and had a bridge built on its north side which took the name of Ponte di Porta Lecce. The canal is currently 810 metres long, 59.40 metres wide and 12 metres deep.

11. This summarises the aesthetic and spiritual experiences derived from architecture. Cf. R. Gargiani, "Genèse et représentation de l'espace indicible," in Le Corbusier, Mesures de l'homme (ed.) F. Migayrou and O. Cinqualbre (Paris: Centre Pompidou, 2015). 

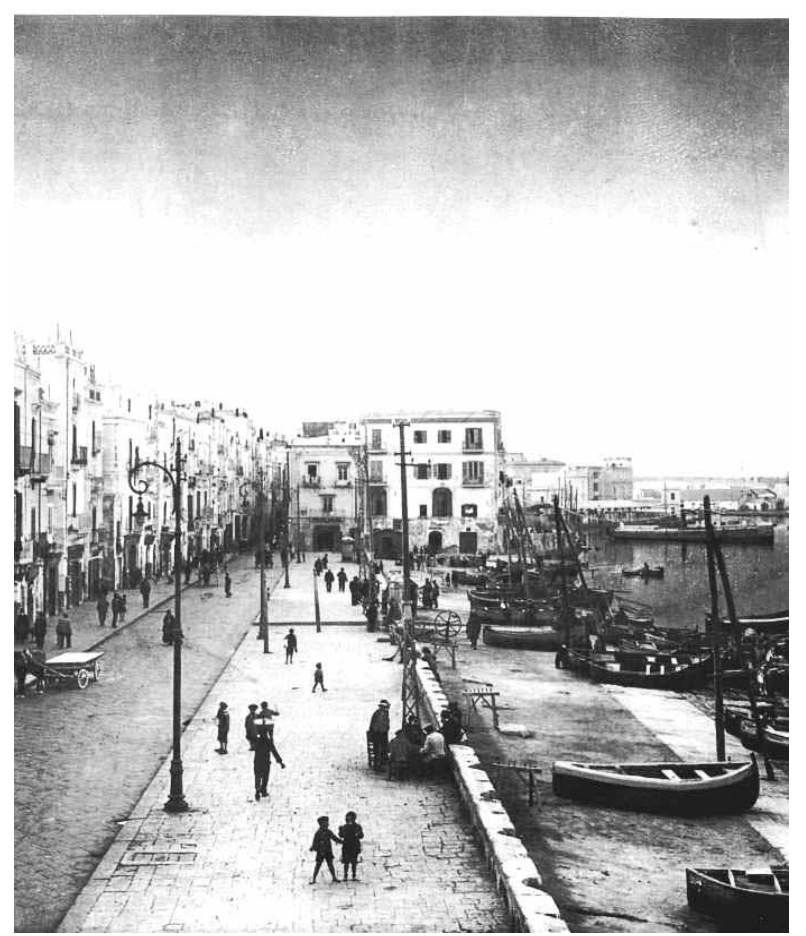

Figure 4. 1910 Via Garibaldi

There is a connection in this place which is based on an eternal law, ${ }^{12}$ between territory ${ }^{13}$ and time (Figure 4). The concept of the passing of time is safeguarded in a sort of primer inherited from a stratification of childhood memories, from a digging into constant remembrances which architecture is full of. The presence of actual layers which have generated a connection between imagination and autobiographical memory in order to recognise the land as expression of the profound narrative on which to rebuild, in the lost landscape, the traces of architecture.

The landscape of the city, as well as that of the whole Gulf of Taranto, seems to me to be almost inscrutable, always in search of a nostalgic connection, of an Odysseian nostos, ${ }^{14}$ desperately seeking an opportunity to forestall oblivion.

At the same moment in which Argan speaks of cultural infamy, ${ }^{15}$ the Institute for Industrial Reconstruction (Istituto per la Ricostruzione Industriale, IRI) was filming a splendid documentary on the great landscape and geographic transformation, on the new metallic topography that was about to replace the pages written by the ancient masserie.

The dry voice of the narrator describes the arrival of the excavator:

12. The word "eternal" refers to Pagano's introduction: "The aim of this work is to find the eternal law that has created wonderful documents in the history of man" in G. Pagano and G. Daniel, Architettura rurale italiana (Milano: U. Hoepli, 1936).

13. By territory is understood the synthesis of land and sea, both solid places on which to build and contrast the language of architecture.

14. A voyage in time which is rich in images, events and vicissitudes.

15. G. C. Argan refers to the IV Polo Siderurgico ex Italsider. 
"Sheep, olive trees, burnt ground from from which white rock surfaces, and in the background the sea. A hot, intense sea. These are the protagonists of a millenary story whose rhythm is marked by the equal and monotonous arches of the Mediaeval aqueduct which ran toward the hills of Ionic Puglia and which today is witness to a lost age. [...] And suddenly a new force: the machine. Centuries-old olive trees fall like wooden marionettes. The old white houses of peasants and shepherds tumble to the ground.",16

The oxymoron oscillates between a sense of detachment and the will to keep intact the fragments of this land, the roots of an immense Mediterranean koine. ${ }^{17}$ An alternation between visual and spatial narratives, in which architecture takes on the role of hinge in the (wrongful) re-appropriation of the territory itself. A constructive act which is ready to erase all, to let everything sink into the saddest amnesia.

Action. The deep understanding of the canvas on which to design projects and urban knowledge derives precisely from the will to reconstruct an image of the landscape, through an operation which fixates the senses and feelings that are capable of triggering a new beginnig for inhabiting the land through architecture. The execution of projects, or rather the architectures themselves, have taken possession of the geographical landscape and have become the essence and synthesis of the territory. Almost as if through a moment of epiphany, the fragments have attempted to mend the space of the Old City, reinstating it and grasping in words and meanings a sense of respect for the values which exist between man and building.

The clear surface seems to have distanced and separated the worlds of that which was and that which seems no longer possible. It is in fact the slow movements of this "land" in perpetual motion which have indirectly distanced its inhabitants from their origins. Walking down the streets, where the narrow alleys are coloured with the gold of the carparo, ${ }^{18}$ one understands how the vision of the building elements, recovered in the shapes of the endless shadows, emerge from the buildings themselves. The Old City in fact appears as a single block of stone which literally lies on the water, from whose bowels only the necessary spaces for the lives of men were excavated from the rich and porous carparo.

These are environmental issues which have an effect on the poetic ruin, ${ }^{19}$ on the patina of salt carried by the soft winds that come from the Mar Piccolo and the Mar Grande and which meet in the Canal.

The history of the ancient centre, however, recalls Patrizia De Luca, "is tormented, made of continuous subversions of power, of changes of direction, of unceasing successions of peoples and cultures, to such an extent that today's

16. The institute devoted a beautiful documentary to the construction of the great industrial complex, considered at the time as both the future and the motor of the Mezzogiorno, a vision paradoxically opposed to the current general opinion on the matter.

17. Common language, as linguistic usage accepted and followed by an entire national community on a relatively extended territory with uniform traits.

18. Carparo is a calcarenite derived from the hardening of calcareous rock sediments, usually in marine environments.

19. Cf. A. Martinez Riggen, Luis Barragan. Opera Completa (Milano: Electa, 2005). 
contradictions seem to be the perpetuation of an eternal sequence of events, of a destiny of uncertainty which the city has been incapable of avoiding for centuries." 20

Yet reconstructing the image of the ancient settlement through the traces that are still legible is truly complex. The current built configuration, fascinating for reasons both of sign and design, is the result of an uninterrupted and often haphazard superposing of urban interventions through which, in the continuous process of demolition and reconstruction, often using architectural remains of varied origin, many presences from the past were cancelled. ${ }^{21}$ The Byzantine rock substituted by the Aragonese Castle under the Temple of Poseidon, are some of the elements which alternate between the absence and the presence of what once was. An apparently exhausted city, in which the great architectural structures, which have been built in it, are suspended in time. Time that gazes, time that fixates.

The constructive and architectural process has thus generated a fantastic landscape made of buildings within buildings, each a part of a preceding and forgotten ruin in which past layers are the foundations of the new. Slow Mediterranean movements which shift surfaces.

The presence of typological layers, which are often blind, has made it necessary - in the name of the first and natural childhood discoveries - to start anew from the rich surviving elements, slowly looking in another direction, listening to the silent voice of the collapsed walls and of the fragments which are re-emerging from the earth in order to narrate their own story ${ }^{22}$. This measure repeats itself in a sort of urban rhapsody capable of generating new stanzas to look into.

Disassembling existing architectural structures for unveiling their secrets and those of their inhabitants, for investigating the truth which at every level and every new house obtained have given meaning to the work to be undertaken, the "worksite" to be prepared. As in an atelier, every single piece has been analysed and reconstructed in order to understand in depth how to look with new eyes to the place of the new architecture, where the practice of good dwelling should have marked only the beginning of tomorrow.

Thus, only passing through the elements of which the city is composed - the true city, made of houses and people -, is it possible to understand in depth the reality of this land. There, encountering a group of children on the street kicking an improvised football, it is possible to stop and listen to their screams which are telling us that "Taranto is not only ILVA"; those children who have been waiting since birth for new accesses to reality. It was this apparition made of bodies and words on via di Mezzo, during the survey campaign, that helped us overcome forgetfulness and made us all understand how the dream of this part of the

20. Cf. P. De Luca, Taranto. L' isola (Taranto: Scorpione Editrice, 2001).

21. Ibid.

22. This surfacing is due mainly to cultural associations and to citizen volunteers who over the past few years have attempted to rehabilitate entire sections of the city. In this way a series of very ancient spaces have been recovered which carry a great narrative and educational force. 
Mediterranean is that of inhabiting once again the bodies, the spaces, the objects and the images of thr landscape. ${ }^{23}$

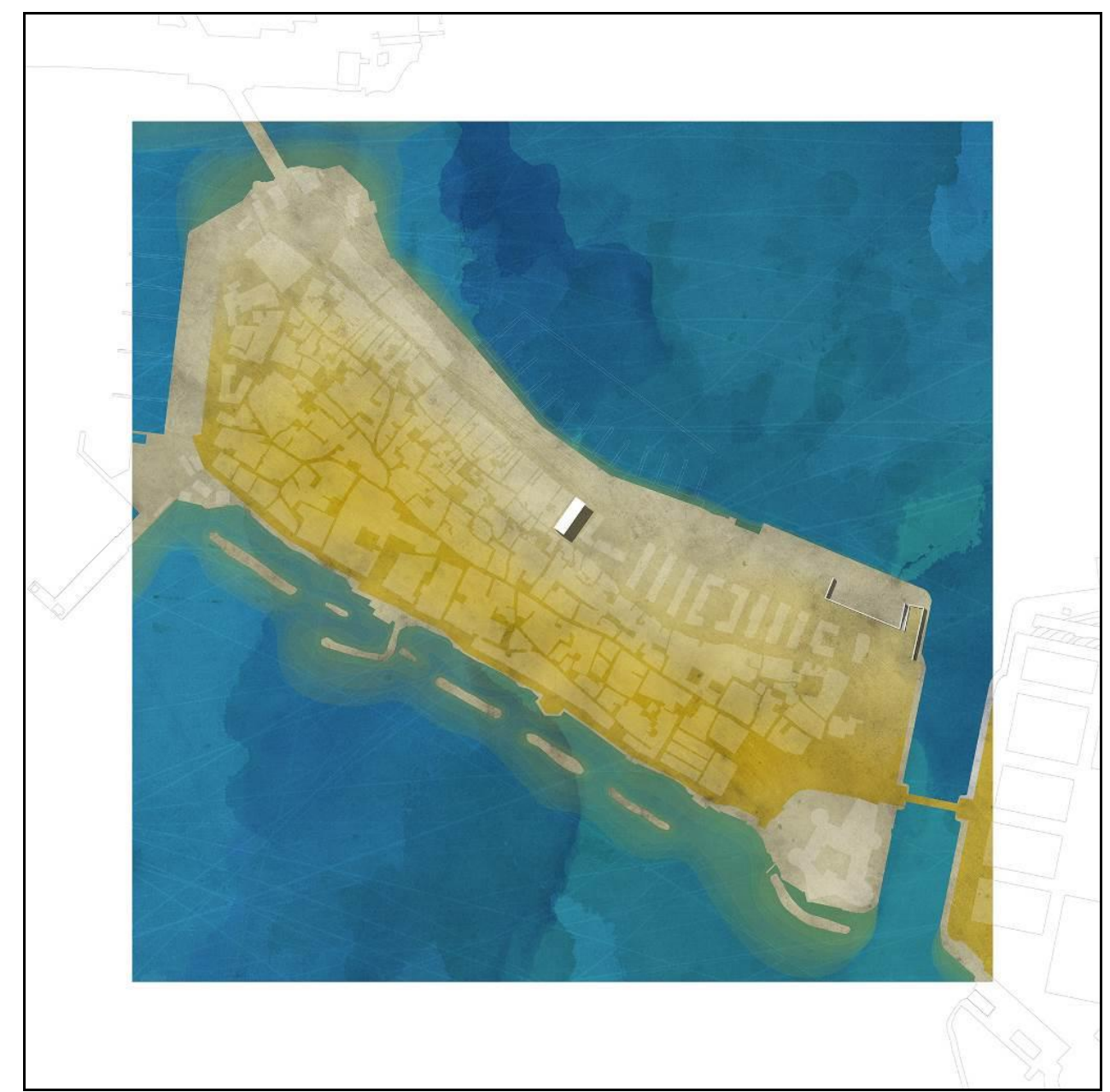

Figure 5. Iconography of the Fish Market

\section{Common Ground: The loggia del Pesce as an Exercise in Compensation}

At the threshold of the $21^{\text {st }}$ century Aesopos and Simeoforidis tell us in Landscapes of Modernisation $^{24}$ of a new geography, understood as an architectural and landscape fact, embedded in memory. Examples which establish - and this is the basis of the project presented - a relationship between architecture and landscape with the intention of verifying and reviving a dialectic connection between the new and ancient urban fabrics.

In the interpretation of the city, and not only of its most ancient section, it was sought to recompose and search for the pieces, using Rilke's beautiful definition in

23. Cf. M. Vitta, Dell'abitare: corpi, spazi, oggetti, immagini (Torino: Einaudi, 2008).

24. Cf. Y. Aesopos and Y. Simeoforidis, Landscapes of modernisation: Greek architecture 1960s and 1990s (Athens: Metapolis Press, 1999). 
his Florentine Diary (originally published in 1898) ${ }^{25}$ in which he compares museums to pages ripped out of books and put back together more elegantly. Moving along the wharf of the Mar Piccolo where, according to Guido Piovene "the best of the life of Old Taranto" 26 is found, in other words between the wall of houses and the sea, there is the church of San Giuseppe, built in the $16^{\text {th }}$ century, which for many centuries was the religious congregation for the fishermen of the city. The church was the only structure that survived the Piano di Risanamento of the Fascist era which began in the early Thirties and was interrupted - fortunately - as a result of World War II. Time, however, has excavated into the matter leaving only a void around the religious building.

The disorder and chaos, which are certainly part of the daily life of a Mediterranean city, characterise the road that separates the inhabited area from the sea; boats arrive constantly, carrying fish to be sold. The scene that appears before the eyes of passers-by is the same as it has been for years, precisely because the essence of the fisherman and of the sale of fish as a ritual - despite the arrival of "steel" - has not changed; among tunas, mussels and other molluscs, the market has always been a timeless necessity. This is the measure of the time from which to learn the lesson of reconstruction, placing the qualitative needs of dwelling before speculative interests.

Thus the fish market is now located at the place where the old congregation gathered, next to the place where the last church stands that survived the disembowelment carried out during the Fascist era (Figure 5). At the intersection of the four pittaggi ${ }^{27}$ the new collective nucleus becomes the fulcrum for the entire surrounding inhabited area. The foundation for the project of a new architecture begins with the study of the measures of the Doric temple from the Classical period. Only a few metres away from there the still impressive presence of the columns belonging to the Temple devoted to Poseidon ( $5^{\text {th }}$ century B.C.), has a decisive influence - through measure and composition - on the project. The golden ratios, the heights and the design itself carry with them the strong heritage of the context, interpreted through current needs.

25. Cf. R. M. Rilke, Diario Fiorentino (Milano: Cederna, 1950).

26. "Yet the best of life in Old Taranto is outside, on the wharf, between the wall of the houses and the Mar Piccolo. [...] Perhaps because the goods are offered and sold using old methods, there is here a true communion between the port, the people who shout, and the sea bottom. [...] This small Oriental port, this population of fish and molluscs, is one of the best Italian memories". In G. Piovene, Viaggio in Italia (Milano: Arnoldo Mondadori, 1966), 607 - 608.

27. This is how the (four) neighbourhoods of the Old City are called. The old city had four rioni, or quarters, which were called "Pittaggi" (from Pittacium), a word derived from the papyri on which births, deaths, marriages, as well as the name of the sick and the assisted were registered. The names of the rioni were: San Pietro, Baglio, Ponte and Turripenne. In the first two pittaggi (those situated in the upper part of the old city) lived the nobility and the bourgeoisie, in the other two, which faced the mar Piccolo, lived the common people. In the latter of these two, more or less where the discesa Vasto is located, was the Jewish ghetto. Each pittaggio was linked to a church: the Cathedral, Sant'Agostino, San Domenico and San Giuseppe, whose deputy parish priest was called pittaggere. 


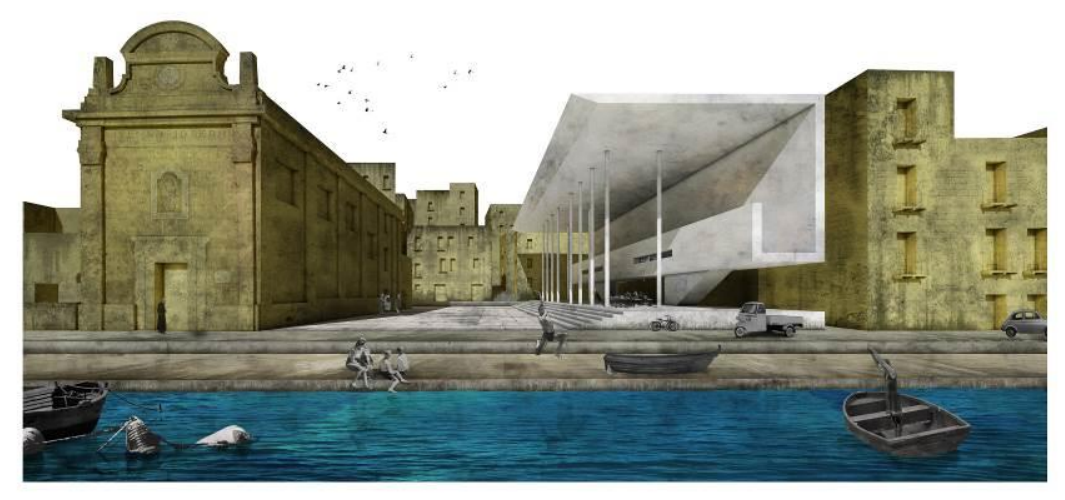

Figure 6. "Sea Perfume", View of a Project

Built from the podium, in accordance with Greco-Roman canons, the new temple to the sea stands between the church and the row of houses that have resisted to the passage of time; here 12 pillars with a height of 8.47 metres - as in the temple to Poseidon - outline the market and construct a covered space between the square and the city. The base of the structure respects the separation between earth and sky as it did in the Greek era, where the need of a suspension between the new and the old city attempts to sacralise the commonplace activity of selling fish. The religious interpretation becomes here a sacralisation of the historical liveliness of the fisherman. The market is situated at a higher level than the ground floors of the houses nearby, thus overcoming - despite its classical measures - the "novelty" of its being located in this place. The construction of the new market is thus actually established from the base of the structure, which transmits the sense of respect for the various historical layers of the city; the crepidoma and the stylobate interact with the square/toloneum which connects the "new" to the church and vice versa. The interpretation of the space between the buildings is organised precisely by the toloneum, a large and ample square that fosters the dialogue between the "scene" of the city which scrambles over the topography of the terrain and the fish market. The pavement, separated from 
the street by way of a compositional detail, connects through its design to the chromatism of the new loggia of the fishermen.

The base, made of stone and with a small flight of steps on the side of the church, concludes with its stylobate, which houses the joints of the pillars of this contemporary naos. The vertical elements design and organise the commercial spaces and establish a relationship with the pre-existing classical settlement. The rhythm of the pillars determines a new space: a raised square with a continuous and uninterrupted roof. The shadows, even more pronounced in a Mediterranean city, are sharp and extended. The roof turns on itself and creates a loggia, as in the southern tradition, a space that is not unlike the matroneum of Christian origin, which houses a public space from which to look over and observe, almost as though from outside the narrative, the activities that go on in the area below. Ascending by way of the load-bearing stairs the new level of the city is reached, a residential area that never enters in contact - except visually - with the market. Everything, including the upper level, remains detached from the structure because the only foundation element is the base. The space of the loggia becomes compressed, the shadows darker, the interpretation is axial (Figure 6).

Here in the fish market, architecture reinstates the missing link between the earth and the sea. Its placement at the centre of the island, at the intersection of the four pittaggi of the Old City, bears witness to the importance, or rather the need, to recreate a collective space that not only serves its function from sunrise to sunset, but which also becomes a place for social interaction, essential to the process of cultural rehabilitation of this section of the city.

In this context it is worth mentioning the reaction of the candle that lights up again by simply blowing on its fumes a few seconds after having put it out. Perhaps a change triggered by architecture could reconstruct the image of the city even through the design of a fish market, an intervention that serves as compensation for the population and which through its inherent form includes the essence of this place, the reason why - day after day - it continues to live despite the difficulties derived from a time that is no longer capable of making space for those things which mankind has periodically depended on in order to find itself.

\section{The Digital Survey in East Jerusalem ${ }^{28}$}

On the other side of the Mediterranean, though not properly overlooking the sea, we find Jerusalem, the Holy City for the three great abramite religions that have alternated in the occupation and administration of its territory throughout history. In the modern era, after the British armistice of 1949, the city was divided by the UN in two parts: to the west the modern part entrusted to the emerging Israeli state, to the east the territories entrusted to the Palestinians, as well as to the old city, surrounded by ancient walls, as a corpus separatum. As it is well known, this political plan is the source of the conflict between the Jewish and Palestinian people, which in 1967 led to the Israeli occupation of most of the Palestinian territories that are recognized still today as occupied areas.

28. The author of this paragraph is Matteo Bigongiari. 
With this political status, Jerusalem today is clearly divided between the East (occupied) and the West, between the two main and profoundly different cultures that divide the city. In the eastern sector, the PURE project, ${ }^{29}$ initiated by UNDP, started with the aim of studying the hypothesis of requalification of an entire urban sector; the project aimed at the upgrading of this urban area that has developed along the main routes of access to the gates of this side of the Old Town, starting with the survey of the area, integrating diagnostic and structural analysis, leading to the recovery of buildings.

The project area is made by two main daily traffic arteries in the eastern sector: Sultan Suleiman Street, which develops along the perimeter of the old city walls from Damascus's gate to the Herod's gate, and Salah Eddin Street that develops orthogonally to the walls, starting from this last gate, intersecting the road described above. Since the Second World War these two paths represented and still represent the life and business hub in East Jerusalem: throughout the day, the ground floor of the buildings along the road are livened by shops and sales, recreating a new Arab suk extra moenia formally different, container and traffic are much more modern, but ontologically identical to that in the old city. It is especially noticeable in the evening, when the activities end, people disappear, ${ }^{30}$ and on the street there are the remains of business: garbage left on the ground carelessly.

Survey operations in this case have the purpose of documenting the buildings and generating a whole package of technical drawings in order to support the analyses of the state of conservation of the buildings. The perimeter of the area to be measured includes the section of Sultan Suleiman Street that goes from the bus station to the Herod's gate, and about 200 meters from the same door sloping orthogonally along Salah Eddin Street.

Between the two traffic arteries there is Bab Azhar's muslim cemetery, one of the oldest in the city: a true hill on the edge of the walls, probably used originally for the extraction of building materials. ${ }^{31}$ In recent times, the Protestant confession identified propitiously in this hill the site of the Holy Sepulcher, relying on the hypotheses of the skull shape that is impressed at the rocky caves. The urban development of the modern city has foreseen the expansion of the stretch along the walls, probably replacing some pre-existing Ottoman buildings, ${ }^{32}$ and filling the area that separated the buildings from the cemetery; later the development proceeded in the orthogonal direction, still next to the perimeter of the cemetery hill, forming Salah Eddin Street. The evolution of the political situation has over

29. Project Research Officers are Stefano Bertocci, Michelangelo Pivetta (DIDA University of Florence) and Sandro Parrinello (DICAr University of Pavia). Coordinators of the various operations: Francesca Picchio (DICAr University of Pavia) for Digital Survey and Documentation, Giovanni Minutoli (DIDA University of Florence) for Structural Analysis.

30. This is a typical feature of Jerusalem: the Palestinian population feels occupied and in the evening, after work, they all retire home, both inside and outside the old city.

31. Jerusalem has been built entirely with local limestone, which is abundant in all the surrounding area, some caves beneath the cemetery graveyard show the regular signs due to the excavation quarry activity.

32. The corner building between Sultan Suleiman and Salah Eddin Street incorporates a portion of the facade of a former Ottoman building. 
time completely saturated the spaces between urban aggregates, over the roofs and the space of respect between the buildings and the containment wall of the cemetery. Anthropic degradation is clearly visible on the side street facades that have "embellished" with electrical systems and open ventilation. Leaning to the cemetery there is also a mosque from whose minaret you can enjoy a full view of the old town and its monuments.

The area survey analysis project envisaged the use of integrated acquisition methodologies (laser scanner and S.f.M.); the first problem to be solved in the design of the survey was how to create a reliable across the urban area, both morphologically and qualitatively, information database. As regards the morphological survey, the state of the art on data acquisition methodologies imposed the use of a laser scanner; unfortunately there was no support for the total station, so specific solutions were adopted to ensure the reliability of the final model. In addition to the laser data, points clouds were made from SfM software to describe the color data of the facades.

First, in order to gain insight into the area, full and empty spaces, aggregates and building units were classified on an aerial plan, further subdividing them according to the number of fronts present, so as to verify that the acquisition of all the surfaces had been done correctly. From this first analysis emerged that the morphological simplicity of the side street facades hides from the opposite side a complex distribution of accretions that have modified the original perimeter.

The laser scanner survey project has had to take into account all these aspects; for this mission a Phase-shift laser scanner Z + F Imager 5006h was used (provided by the University of Florence studies), whose features are a high cloud acquisition speed (up to one million points at Second) and a nominal scan rate of $78 \mathrm{~m}$. On the basis of the plan data provided by UNDP, it was possible to study the distribution of scanning positions: in order to solve the problem of the reliability of the survey of such a large area, it was necessary to first try to connect the two blocks between them to close a polygon of scan stations and thus allow to calculate metrically how much misalignment occurred during the registration. It was decided to join the link through a block of scans that passed through the cemetery and connect the square behind the bus station on the one side, on the other Salah Eddin street. The polygon was used as a basis for supporting all remaining scans; as well as the street survey, which has no particular complexity, it was necessary to scan the whole area inside the cemetery: the interior front of the buildings is visible only on that side. The survey of the burial area was then tied to secondary scans of the main polygon, dividing the cemetery into segments, thus controlling rotational errors in the alignment phase (Figure 7). 


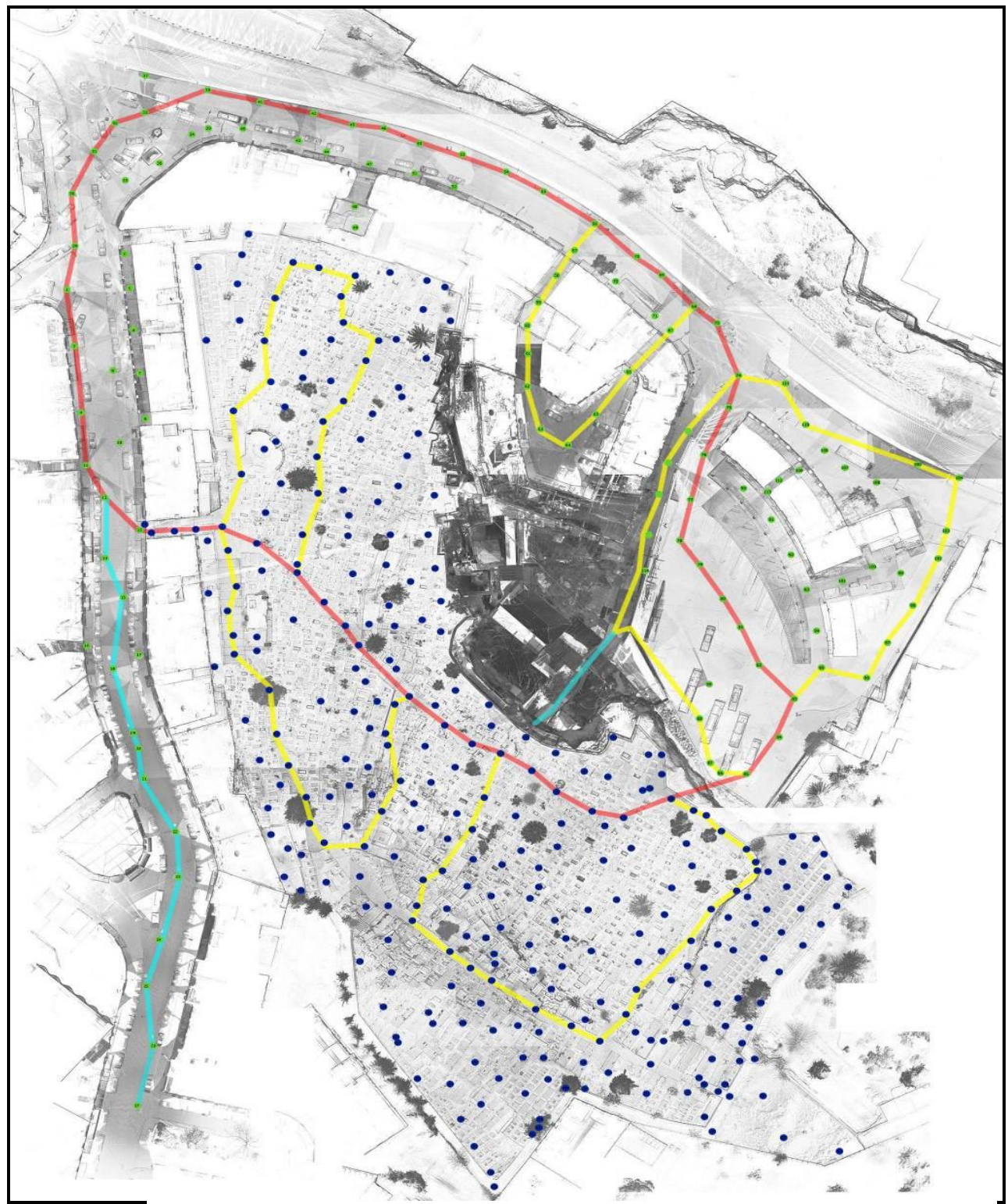

Figure 7. Planimetry with Scanning Project: in Red the Main Polygon, in Yellow Secondary Polygons, in Cyan Free Blocks

For even greater control of the error, high resolution scans ${ }^{33}$ have been made from some strategic points such as building shells, direct road-cemetery links, and minarets linking the cemetery with the mosque and the station. In the first phase of data acquisition, ${ }^{34}$ we did not focus on the interior of the buildings, limiting the survey to the outside only.

33. High resolution scan is a scan that creates a mesh of points at the distance of 10 meters of the laser beam emission point, spaced between them $3 \mathrm{~mm}$

34. The laser scanner area survey was carried out during January 2016, a second mission, mostly to complete diagnostic and structural investigations, took place in June 2016 


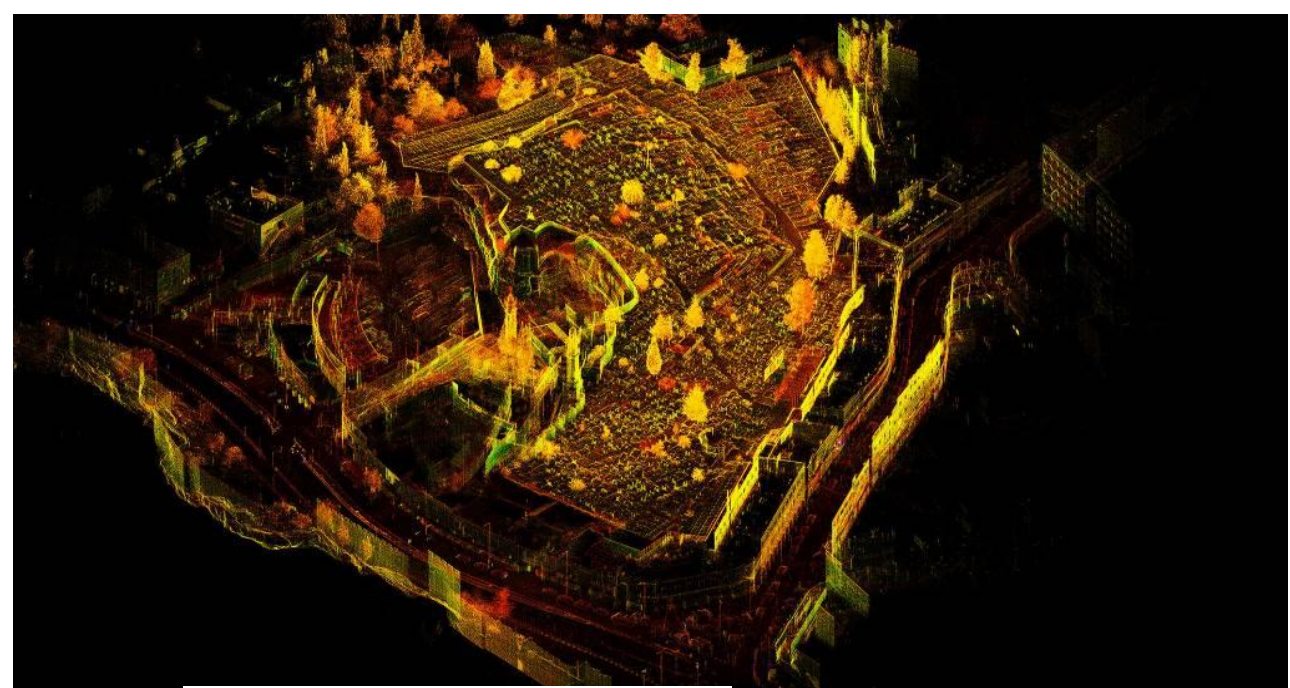

Figure 8. View of the General Point Cloud

After completing the approximately 500 scans, two-thirds of which concern the cemetery area, the registration phase of the survey began. To connect the scans, mass-target targets were used, identifiable up to $30 \mathrm{~m} ;{ }^{35}$ At first, scans of the fundamental polygon were recorded, so that the basis of the survey was created; Subsequently, secondary blocks were linked to it, and the scans used to densify the data of the clouds, describing all the surfaces of the objects. ${ }^{36}$ In addition to using black and white targets to optimize alignment, cloud-costraint has been added to the scans that are adjacent to each other and distant less than 10 meters apart; In this particular case, the cloud to cloud process had a better effect along the road survey: the graveyard area, where the vegetation is very lush, has got greater overall errors on the movements of all the points in the cloud (however, always inside of a range up to $1.5 \mathrm{~cm}$ ).

After the registration phase, it was checked that the scans rotated correctly on a single model: this phase, defined as "collaudo" of the point cloud, is highly required $^{37}$ and involves the realization of vertical and horizontal sections that investigate the points of the architecture and verifying how much the crosssectional threads of the various scans are misaligned in meters. The error is within $1.5 \mathrm{~cm}$, the maximum limit for the 1:50 scale representation of buildings.

Once a complete and reliable model has been obtained (Figure 8), for an agile 200GB point database management, the cloud has been divided by level, one for each scan; In this way the transition from $3 \mathrm{D}$ to $\mathrm{CAD}$ to redesign architecture has been greatly simplified: during the rasterization of the cloud in orthoimage,

35. All scans have been made at least with a resolution that creates a mesh of points at a distance of 10 meters from the laser beam emission point, $6 \mathrm{~mm}$ apart; at this definition the targets are visible up to $30 \mathrm{~m}$ if collimated with orthogonal radius to the target plane.

36. G. Pancani, "Il rilievo laser scanner della cattedrale di Sasamón," in Complessi religiosi e sistemi difensivi sul Camino di Santiago de Compostela: Rilievi e analisi per la valorizzazione e il restauro della cattedrale di Santa Maria la Real a Sasamón (ed.) S. Bertocci, G. Minutoli, S. Mora and G. Pancani (Firenze, 2015).

37. Single scans have millimeter reliability, but the registration process in one model does not follow certified procedures. Pancani, "Il rilievo laser scanner della cattedrale di Sasamón,” 2015. 
the ability to keep a part of the scans in the display speeds up the transition from cloud to image. For each front of buildings, a section plan has been set so that the true size of each surface can be restored; the contour profiles, the grooves, the fixtures, the plants and so on from the orthoimage have been redrawn in CAD environment on a layered drawing sheet useful to describe the components of architecture in the best way. The critical redraw work has made it possible to create the basis of two-dimensional morphological elaborations on the basis of which the diagnostic analyzes are subsequently redeemed. Two-dimensional elaborations were integrated with the colorimetric data using the SfM detection systems; for each front of the buildings, a set of photographs was taken to rebuild a three-dimensional model to apply the actual texture of the object. From the 3D models thus obtained, following protocols to ensure its metric reliability, ${ }^{38}$ orthophotopses were extracted, thus completing architectural survey information.

Parallel to the design of urban fronts, a number of environmental scales have been realized on a scale of 1:200, useful in describing as a whole the area under analysis and the spatial relationships between the different architectural and distributive systems between full spaces and voids, highlighting the different levels of the ground level (Figure 9). The drafting of these drawings is not so fundamental to the analysis carried out on the buildings, but still provides a useful landscape reading tool.

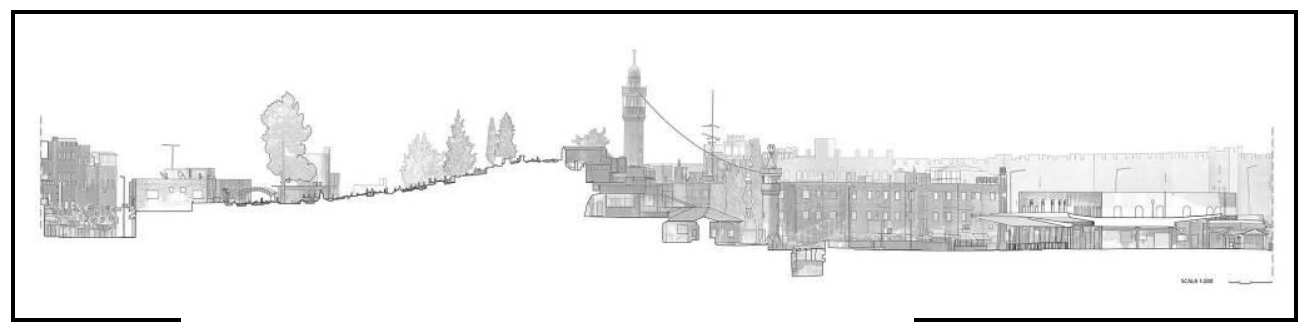

Figure 9. Environmental Section across the Cemetery

In addition to the creation of a morphological database concerning the project area, to complete the information obtained from the urban survey, standard types have been defined for each aggregate and the urban front of the buildings. Thanks to the data collected in the schedules, it was possible to integrate this qualitative information that cannot be detected by the surveyer design: the use of premises, the catalog of building elements, openings, the general state of conservation, and more. ${ }^{39}$ The same type of analysis was also carried out in the cemetery: for each burial slab a special sheet was made, describing its type and state of conservation. The interactive census system also has the advantage of being continuously

38. Each model was scaled on the metric point of the point-cloud from the laser scanner, using at least four homologous points per chunk for this process; the result obtained has made errors not exceeding $2 \mathrm{~cm}$.

39. S. Parrinello, M. Bercigli and R. De Marco, "Gerusalemme est: sistemi cartografici 3D per il censimento urbano e di siti monumentali islamici," in Proceedings of the REUSO International Conference. V Congreso Internacional sobre documentación, conservación y reutilización del patrimonio arquitectónico y paisajístico (Granada, Spain, 2017). 
updated in the digital world: the customer is provided not only with information related to the state of facts but also a useful tool that can be upgraded over time.

The large amount of information thus collected was subsequently correlated to a three-dimensional schematic model, representing the project area, using 3D GIS cataloging systems; This tool allows to link the three-dimensional model surfaces with censorship information, thus obtaining an interrogative $3 \mathrm{D}$, thus useful to return thematic maps both in plan and vertically, showing the required information from time to time.

The Salah Eddin Street and Sultan Suleiman street documentation project has been completed by integrating the diagnostic analyzes of surface degradation, based on the material drawings and on-site surveys, and the deformational analyzes obtained through the elevation map method directly from the point cloud; this research base has been the basis for the structural analysis carried out in the second mission that added information on the interior and building structures to external information. ${ }^{40}$

In conclusion, thanks to the use of appropriate procedural protocols, it was possible to obtain a very reliable three-dimensional morphological base of the analysis area from which to extract the two-dimensional elaborations needed to describe the architectures and to drain the diagnostic analyzes; The use of censorship cards has kept the memory of those non-metric but qualitative information that is fundamental to the description of the life of East Jerusalem.

\section{Conclusions. Coming Back to Some Interrupted Discussions ${ }^{41}$}

Events have always taken place along the shores of the Mediterranean which have determined its essence. The construction of its landscape, through complex topographies, has generated settlement systems of great interest to architecture. Fortified cities, small villages, have created a highly interesting fabric that time seems to have forgotten in the name of a necessary contemporariness that is capable of erasing places and realities of unparalleled splendour.

It is evident how a world is disappearing. A world in transformation in which the fabric of historic cities seem to turn into abandoned archaeologies dominated by the weight of successive eras. "Urban archaeologies" are buried under their own landscapes, forming a canvas of apparently erased and unfathomable memories. This is the sense of the educational mission aimed at the valorisation of memory and the recovery of those aspects in which value becomes virtue, becomes a lesson in architecture.

The structure of the Old City of Taranto and of East Jerusalem offer the opportunity for the cataloguing of elements, of constructions capable of narrating

40. S. Bertocci, G. Minutoli and M. Bigongiari, "Il rilievo strutturale per l'analisi della stabilità e vulnerabilità degli edifici lungo Salah Eddin street e Sultan Suleiman street a Gerusalemme Est," in Proceedings of the REUSO International Conference. $V$ Congreso Internacional sobre documentación, conservación y reutilización del patrimonio arquitectónico y paisajístico (Granada, Spain, 2017).

41. The author of this paragraph is Vincenzo Moschetti. 
their educational and spacial autonomy. The state-of-the-art laser survey campaigns have led subsequent studies toward more important discoveries, offering a clear pathway that demonstrates the value of these sites. In a certain sense the possibilities offered by these tools have produced a second useful map for carrying out interventions which re-propose a catalogue of the real. It was then possible to contrast the projects with their spatial qualities, recovering in the compositional aspects the architectural truth of every single part. Typologies, fragments and elements have come to light once again to become a part of those sunken worlds.

It could be said, paraphrasing a well-known excerpt from the Epistle to the Hebrews $(X I, I,)^{42}$ how the determination was that of giving substance to things hoped for as evidence of things which are (apparently) invisible. The fragments of landscape of the cities of Taranto and Jerusalem are reflected in a sort of spiritual system of things through the Mediterranean mirror, in which the gaze makes us understand how necessities are not so different, despite the great geographical distance.

\section{Bibliography}

Aesopos, Y. and Y. Simeoforidis. Landscapes of modernisation: Greek architecture 1960s and 1990s. Athens: Metapolis Press, 1999.

Alberti, L. B. "De Re Aedificatoria" [About Building.] In Trattati di Architettura. Edited by R. Bonelli and P. Portoghesi. Milano: il Polifilo, 1966.

Bertocci, S., G. Minutoli and M. Bigongiari. "Il rilievo strutturale per l'analisi della stabilità e vulnerabilità degli edifici lungo Salah Eddin street e Sultan Suleiman street a Gerusalemme Est" [The structural survey for the analysis of the stability and vulnerability of buildings along Salah Eddin street and Sultan Suleiman street in East Jerusalem.] In Proceedings of the REUSO International Conference. $V$ Congreso Internacional sobre documentación, conservación y reutilización del patrimonio arquitectónico y paisajístico (Granada, Spain, 2017).

De Luca, P. Taranto. L' isola [Taranto. The Island.] Taranto: Scorpione Editrice, 2001.

Galateo, A. Del sito della Iapigia: Epistola [From the Iapigia site: Epistola.] Napoli: stamp. di Gaetano Rusconi, 1853.

Gargiani, R. "Genèse et représentation de l'espace indicible" [Genesis and representation of the unspeakable space.] In Le Corbusier, Mesures de l'homme. Edited by F. Migayrou and O. Cinqualbre. Paris: Centre Pompidou, 2015.

Lévy, P. Il virtuale [The Virtua.] Milano: Raffaello Cortina, 1996.

Martinez Riggen, A. Luis Barragan. Opera Completa. [Luis Barragan. Complete Work.] Milano: Electa, 2005.

Pagano, G. and G. Daniel. Architettura rurale italiana [Italian rural Architecture.] Milano: U. Hoepli, 1936.

42. "Est fides sperandarum substantia rerum, argumentum non apparentium." English translation: "Faith is the substance of things hoped for and the evidence of things not seen". 
Pancani, G. "Il rilievo laser scanner della cattedrale di Sasamón" [The laser scanner survey of the cathedral of Sasamón.] In Complessi religiosi e sistemi difensivi sul Camino di Santiago de Compostela: Rilievi e analisi per la valorizzazione e il restauro della cattedrale di Santa Maria la Real a Sasamón. Edited by S. Bertocci, G. Minutoli, S. Mora and G. Pancani. Firenze, 2015.

Piovene, G. Viaggio in Italia [Journey in Italy.] Milano: Arnoldo Mondadori, 1966.

Rilke, R. M. Diario Fiorentino [Florentine diary.] Milano: Cederna, 1950.

Unali, M. Atlante dell'abitare virtuale [Atlas of virtual dwelling.] Roma: Gangemi, 2014.

Vitta, M. Dell'abitare: corpi, spazi, oggetti, immagini [On "dwelling": bodies, spaces, objects, images.] Torino: Einaudi, 2008. 
